Short communication

\title{
Diagnostic yield of five minutes compared to three minutes hyperventilation during electroencephalography
}

\author{
Laura Craciun ${ }^{\mathrm{a}, \mathrm{b}}$, Edina Timea Varga ${ }^{\mathrm{c}}$, Ioana Mindruta ${ }^{\mathrm{b}}$, Pirgit Meritam ${ }^{\mathrm{a}}$, Zoltán Horváth ${ }^{\mathrm{c}}$, \\ Daniella Terney ${ }^{a}$, Elena Gardella ${ }^{a}$, Jørgen Alving ${ }^{a}$, László Vécsei ${ }^{c, d}$, Sándor Beniczky ${ }^{\mathrm{a}, \mathrm{e}, *}$ \\ ${ }^{a}$ Department of Clinical Neurophysiology, Danish Epilepsy Centre, Denmark \\ ${ }^{\mathrm{b}}$ Department of Neurology, University Hospital, Bucharest, Romania \\ ' Department of Neurology, University of Szeged, Hungary \\ ${ }^{\mathrm{d}}$ MTA-SZTE Neuroscience Research Group, Szeged, Hungary \\ e Department of Clinical Neurophysiology, Aarhus University, Denmark
}

\section{A R T I C L E I N F O}

\section{Article history}

Received 7 February 2015

Received in revised form 2 June 2015

Accepted 3 June 2015

\section{Keywords:}

Diagnostic yield

Duration

EEG

Hyperventilation

Provocation

\begin{abstract}
A B S T R A C T
Purpose: To investigate whether hyperventilation (HV) for $5 \mathrm{~min}$ increases the diagnostic yield of electroencephalography (EEG) compared to 3 min HV.

Methods: data were evaluated from 1084 consecutive patients, from three European centres, referred to EEG on suspicion of epilepsy. Seizures and interictal EEG abnormalities precipitated during the first $3 \mathrm{~min}$ and during the last $2 \mathrm{~min}$ of the HV period (totally $5 \mathrm{~min}$ ) were determined.

Results: Eight hundred seventy-seven patients (81\%) completed 5 min HV. Seizures were precipitated during the first $3 \mathrm{~min}$ of $\mathrm{HV}$ in 21 patients, and during the last $2 \mathrm{~min}$ in four more patients. Interictal EEG abnormalities were precipitated in the first $3 \mathrm{~min}$ of $\mathrm{HV}$ in 16 patients, and during the last 2 min in 7 more patients. Psychogenic nonepileptic seizures occurred in eight patients during the first $3 \mathrm{~min}$ of HV and in two more patients during the last $2 \mathrm{~min}$. No adverse events occurred during the last $2 \mathrm{~min}$ of $\mathrm{HV}$, but eight patients (1\%) stopped HV during the last 2 min because they were not able to hyperventilate further.

Conclusion: $16 \%$ of seizures and 30\% of interictal EEG abnormalities triggered by HV occurred during the last 2 min of $\mathrm{HV}$, suggesting the clinical usefulness of prolonged hyperventilation for $5 \mathrm{~min}$. The vast majority of patients (99\%) who are able to hyperventilate for 3 min can complete 5 min HV, without additional adverse events.
\end{abstract}

(C) 2015 British Epilepsy Association. Published by Elsevier Ltd. All rights reserved.

\section{Introduction}

Hyperventilation (HV) is one of the most important provocation methods during standard EEG recordings. Its diagnostic value has been well established in the literature and in the clinical praxis $[1,2]$. HV can precipitate EEG abnormalities and seizures (especially absences), thus increasing the diagnostic yield of EEG $[1,2]$.

The American Clinical Neurophysiology Society, the British Society for Clinical Neurophysiology, the International Federation of Clinical Neurophysiology and the International League Against Epilepsy Subcommission on European Guidelines recommend performing HV as a part of the standard EEG recordings [3-6]. However there is no consensus on the necessary duration of the

\footnotetext{
* Corresponding author at: Visby Allé 5, 4293 Dianalund, Denmark. Tel.: +45 26981536

E-mail address: sbz@filadelfia.dk (S. Beniczky).
}

HV: some guidelines recommend 3 min [6], or a minimum of 3 min [3], while others recommend that HV is performed for three to 5 min [4].

Several studies addressed the diagnostic usefulness of HV during EEG. In most of these studies the duration of the HV was 3 min $[2,7,8]$, in one study it was 4 min [9], and in another study 5 min HV was performed [10]. The duration of the HV varied between 3 and $7 \mathrm{~min}$ in a recently published study [11].

However, the impact of the duration of HV on the diagnostic yield has not been systematically investigated yet. The goal of our study was to elucidate whether HV for $5 \mathrm{~min}$ increases the diagnostic yield of electroencephalography (EEG) compared to 3 min HV.

\section{Methods}

Three European centres, where local guidelines included 5 min of $\mathrm{HV}$ as part of the standard EEG, participated in the study. EEG 

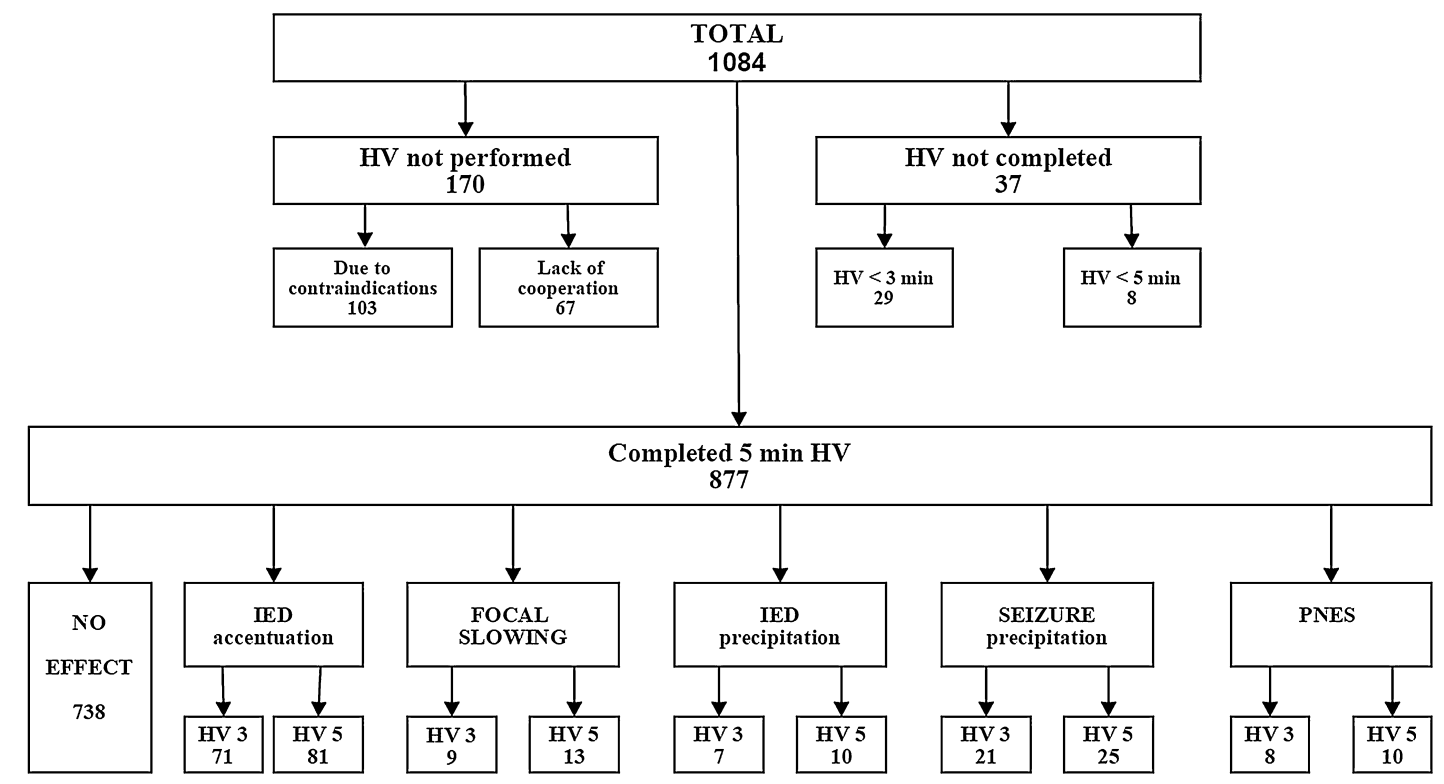

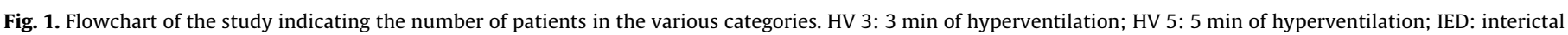
epileptiform discharges; PNES: psychogenic non-epileptic seizure.

recordings from 1084 patients (595 women; age: 1-91 years, mean: 33.8 years) referred on suspicion of epilepsy were prospectively evaluated by board-certified experts.

All patients gave their informed consent prior to the recordings. EEG was recorded with 19 electrodes (10-20 system) or with 25 electrodes in patients where a focal pathology was suspected (six electrodes in the inferior temporal chain were added to the 10-20 system electrodes). In one centre (Danish Epilepsy Centre) age $>65$ years was also considered a contraindication, according to the national guidelines.

HV was not performed due to contraindications in patients with a recent intracranial haemorrhage or significant cardiopulmonary disease [3]. Patients were asked to perform 5 min of HV in room air, with a respiratory rate of 20-30 breaths per minute, under the supervision of a trained EEG technician. For children we used windmill toys. The procedures were recorded on the video and the performance of the HV was classified as sufficient or insufficient by the technician and then by the physician evaluating the EEG recordings [12]. The physicians graded the sufficiency of the HV by watching the video recordings. Similar to the assessment of the sufficiency of $\mathrm{HV}$, adverse effects were first noted by the technician and then by the physicians.

Occurrence of interictal EEG abnormalities and of seizures was noted separately, for the first $3 \mathrm{~min}$ and for the last $2 \mathrm{~min}$ of hyperventilation. Abnormalities were classified according to the recently published European standard [12]. The interictal EEG abnormalities were classified into two categories: interictal epileptiform discharges (IEDs) and focal slowing (FS). Only unequivocal focal delta activity was considered FS, and special attention was attributed to distinguishing FS from normal hyperventilation response [12].
Precipitation of seizures and of interictal EEG abnormalities during HV was considered when these did not occur in the baseline, unprovoked period. In addition, we noted the cases where an accentuation of the phenomena already occurring in the baseline was observed. As the highest diagnostic added value is for the cases where HV induced precipitation of abnormalities not recorded in the baseline period, we focused our study on this. However, to compare our results with previous studies that lumped together precipitation and accentuation, we also noted the accentuation of the pre-existing abnormalities.

Age had normal distribution in our patient population. We used $t$-test to compare the age of the patients who had seizures or interictal EEG abnormalities only during HV with the age of the rest of the patients.

\section{Results}

Out of the 1084 patients, 877 (81\%) successfully completed 5 min of HV (Fig. 1)

One hundred seventy patients did not perform $\mathrm{HV}$ at all due to contraindications or lack of cooperation. Five patients had cardiovascular disease and three patients had asthma. Ninety-five patients aged $>65$ years were excluded because that was considered contraindication in one of the participating centres. Sixty-seven patients were not able to cooperate to the HV: due to intellectual disability in 58 patients and due to young age $(<1.5$ year) in 9 patients. One hundred seventy-five out of the 877 patients who completed 5 min HV were between 1 and 16 years (Table 1 ).

Thirty-seven patients started HV but were not able to complete it. Twenty-nine patients stopped before reaching $3 \mathrm{~min}$ of HV (3 patients were feeling uncomfortable, 1 patient had tetany and in

Table 1

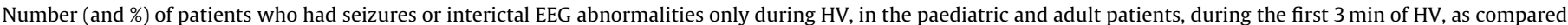
with the whole period of $5 \mathrm{~min} \mathrm{HV}$.

\begin{tabular}{|c|c|c|c|c|c|c|}
\hline \multirow[b]{2}{*}{ Age groups } & \multicolumn{3}{|c|}{ Seizures precipitated by HV } & \multicolumn{3}{|c|}{ Interictal abnormalities only during HV } \\
\hline & $\begin{array}{l}1-16 \text { years } \\
(n=175)\end{array}$ & $\begin{array}{l}>16 \text { years } \\
(n=702)\end{array}$ & $\begin{array}{l}\text { All patients } \\
(n=877)\end{array}$ & $\begin{array}{l}1-16 \text { years } \\
(n=175)\end{array}$ & $\begin{array}{l}>16 \text { years } \\
(n=702)\end{array}$ & $\begin{array}{l}\text { All patients } \\
(n=877)\end{array}$ \\
\hline HV 3 min & $12(6.9 \%)$ & $9(1.3 \%)$ & $21(2.4 \%)$ & $1(0.6 \%)$ & $15(2.1 \%)$ & $16(1.8 \%)$ \\
\hline HV 5 min & $14(8 \%)$ & $11(1.6 \%)$ & $25(2.9 \%)$ & $2(1.2 \%)$ & $21(3 \%)$ & $23(2.6 \%)$ \\
\hline
\end{tabular}


25 patients the HV could not be continued because of lack of cooperation). Eight patients stopped after 3 min of HV and before reaching the $5 \mathrm{~min}$ limit (Fig. 1 ), because they were not able to hyperventilate longer, but no adverse event occurred during the last 2 min of HV.

HV precipitated seizures in 25 patients (2.9\%). In 21 of them (2.4\%) the seizures occurred during the first $3 \mathrm{~min}$ (Fig. 1). Seizures were precipitated in the last $2 \mathrm{~min}$ in four additional patients. Thus seizures occurred during the last 2 min of HV in $16 \%$ of the patients who had seizures triggered by HV. The main seizure-types precipitated by HV were absences (19 patients), followed by myoclonic seizures ( 3 patients) and complex partial seizures (three patients). During the last 2 min of HV two absence seizures, one myoclonic seizure and one complex partial seizure was precipitated. Patients in whom HV precipitated seizures (Table 1) were younger (range: 6-46, mean: 16.2 years) than the patients with unprovoked seizures $(p=0.01)$, and younger than the patients without seizures during the recording $(p<0.001)$.

In the same patient population we recorded 4 absence seizures, 26 myoclonic seizures and 19 complex partial seizures during the baseline (unprovoked) period. Thus most of the absences occurred during HV (19 out of 23).

Interictal EEG abnormalities were precipitated during HV in 23 patients (2.6\%). However, only in 16 patients they occurred during the first $3 \mathrm{~min}$ (1.8\%). Thus interictal abnormalities occurred during the last 2 min of $\mathrm{HV}$ in $30 \%$ of the patients who had EEG abnormalities triggered by HV.

The increase comprised both IEDs (during the first $3 \mathrm{~min}$ in seven patients, and additional three patients during the last $2 \mathrm{~min}$ of HV) and FS (during the first $3 \mathrm{~min}$ in nine patients, and additional four patients during the last 2 min of HV).

The age of the patients who had interictal epileptiform abnormalities precipitated by HV was not different from the rest of the population (range: $13-52$, mean 34.1 years).

Accentuation of the EEG abnormalities pre-existing in the baseline (unprovoked) period was observed in 81 patients (9.3\%). In 71 patients this occurred during the first 3 min (8.1\%).

Psychogenic non-epileptic seizures (PNES) occurred during HV in 10 patients (1.1\%). PNES occurred in the first $3 \mathrm{~min}$ of $\mathrm{HV}$ in eight patients and in two additional patients during the last 2 min of HV. Totally 22 PNES were recorded in our population, thus almost half of them during HV.

\section{Discussion}

We found precipitation or accentuation of the EEG abnormalities during HV in 104 patients (11.9\%) and precipitation of epileptic seizures in 25 patients (2.9\%). This is in accordance with previous studies on the diagnostic yield of HV during EEG [2,7-11].

Extending $3 \mathrm{~min} \mathrm{HV}$ with additional $2 \mathrm{~min}$ proved to be feasible: $99 \%$ of patients who completed 3 min HV were able to continue it for two more minutes, and no adverse events occurred during the last 2 min of HV.

When expressed as percentage of the total patient population, the increase in diagnostic yield seems to be rather modest: from $2.4 \%$ to $2.9 \%$ for seizure-precipitation, and from $1.8 \%$ to $2.6 \%$ for eliciting interictal abnormalities that were not seen in the unprovoked, baseline period. However, this is influenced by the low percentage of patients who had seizure or IEDs only during HV [11]. If we express the difference as percentage of the total number of patients who had seizures or IEDs only during HV, the difference between 3 and $5 \mathrm{~min} \mathrm{HV}$ is $16 \%$ and 30\%, respectively. In other words, if the patients had hyperventilated for 3 instead of $5 \mathrm{~min}$, we would have missed $16 \%$ of the seizures and $30 \%$ of the interictal abnormalities triggered by HV. From a clinical point of view this is an important increase in the diagnostic yield, taking also into account that no adverse events occurred during the last 2 min of HV.

The age of the patients who had seizures precipitated by HV was younger than the rest of the studied population. This is in accordance with previous studies and it is explained by the high incidence of absence seizures in this group (19 out of 25 seizures precipitated by HV).

Another clinically relevant finding in our study was the high incidence of PNESs during hyperventilation: almost half of the PNESs in our study occurred during HV. All patients received written information about $\mathrm{HV}$, and seizure-precipitation was mentioned as a possible effect. The high susceptibility of the patients with PNES could explain why HV elicited these events, based on the information provided to the patients prior to the recording.

\section{Conclusion}

Increasing the duration of $\mathrm{HV}$ to $5 \mathrm{~min}$ is safe and increases the diagnostic yield of EEG recordings compared to 3 min HV.

\section{Conflict of interest statement}

The authors do not have any conflict of interests to disclose.

\section{Acknowledgement}

This study was supported by a grant from the Filadelfia Research Foundation (Denmark).

\section{References}

[1] Binnie CD, Stefan H. Modern electroencephalography: its role in epilepsy management. Clin. Neurophysiol. 1999;110:1671-97.

[2] Mendez OE, Brenner RP. Increasing the yield of EEG. J. Clin. Neurophysiol. 2006;23:282-93.

[3] American Clinical Neurophysiology Society. Guideline 1: minimum technical requirements for performing clinical electroencephalography. J. Clin. Neurophysiol. 2006;23:86-91.

[4] British Society for Clinical Neurophysiology. ANS/BSCN Guidelines for Hyperventilation During EEG Recordings. http://www.bscn.org.uk/content. aspx?Group=guidelines\&Page=guidelines_hyperventilation\%20during\% 20eeg.

[5] Deuschl G, Eisen A, editors. Recommendations for the practice of clinical neurophysiology: guidelines of the International Federation of Clinical Neurophysiology. Second edition, Electroencephalography and Clinical Neurophysiology; 1999 (Supplement 52).

[6] Flink R, Pedersen B, Guekht AB, Malmgren K, Michelucci R, Neville B, et al. Guidelines for the use of EEG methodology in the diagnosis of epilepsy. International League Against Epilepsy: commission report. Commission on European Affairs: Subcommission on European Guidelines. Acta Neurol. Scand. 2002;106:1-7.

[7] Yenjun S, Harvey AS, Marini C, Newton MR, King MA, Berkovic SF. EEG in adultonset idiopathic generalized epilepsy. Epilepsia 2003;44:252-6.

[8] Angus-Leppan H. Seizures and adverse events during routine scalp electroencephalography: a clinical and EEG analysis of 1000 records. Clin. Neurophysiol. 2007; 118:22-30.

[9] Holmes MD, Dewaraja AS, Vanhatalo S. Does hyperventilation elicit epileptic seizures? Epilepsia 2004;45:618-20.

[10] Adams DJ, Lueders H. Hyperventilation and 6-hour EEG recording in evaluation of absence seizures. Neurology 1981;31:1175-7.

[11] Kane N, Grocott L, Kandler R, Lawrence S, Pang C. Hyperventilation during electroencephalography: safety and efficacy. Seizure 2014;23:129-34

[12] Beniczky S, Aurlien H, Brøgger JC, Fuglsang-Frederiksen A, Martins-da-Silva A, Trinka E, et al. Standardized computer-based organized reporting of EEG SCORE. Epilepsia 2013;54:1112-24. 